\title{
Effect of N-2 and Ar gas on DC arc plasma generation and film composition from Ti-Al compound cathodes
}

Igor Zhirkov, Efim Oks and Johanna Rosén

\author{
Linköping University Post Print
}

Tweet

N.B.: When citing this work, cite the original article.

Original Publication:

Igor Zhirkov, Efim Oks and Johanna Rosén, Effect of N-2 and Ar gas on DC arc plasma generation and film composition from Ti-Al compound cathodes, 2015, Journal of Applied Physics, (117), 21, 213301.

http://dx.doi.org/10.1063/1.4921952

Copyright: American Institute of Physics (AIP) http://www.aip.org/

Postprint available at: Linköping University Electronic Press

http://urn.kb.se/resolve?urn=urn:nbn:se:liu:diva-120050 


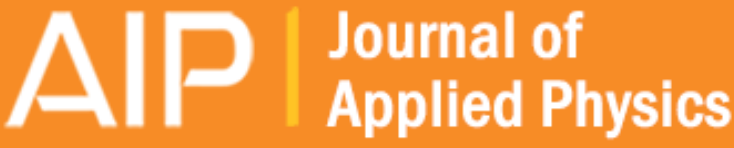

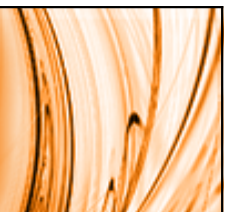

\section{Effect of N2 and Ar gas on DC arc plasma generation and film composition from Ti-Al compound cathodes}

Igor Zhirkov, Efim Oks, and Johanna Rosen

Citation: Journal of Applied Physics 117, 213301 (2015); doi: 10.1063/1.4921952

View online: http://dx.doi.org/10.1063/1.4921952

View Table of Contents: http://scitation.aip.org/content/aip/journal/jap/117/21?ver=pdfcov

Published by the AIP Publishing

\section{Articles you may be interested in}

Effect of Ti-Al cathode composition on plasma generation and plasma transport in direct current vacuum arc J. Appl. Phys. 115, 123301 (2014); 10.1063/1.4869199

Ion velocities in direct current arc plasma generated from compound cathodes

J. Appl. Phys. 114, 213302 (2013); 10.1063/1.4841135

Characterization of plasma chemistry and ion energy in cathodic arc plasma from Ti-Si cathodes of different compositions

J. Appl. Phys. 113, 163304 (2013); 10.1063/1.4802433

Characterization of a plasma produced by pulsed arc using an electrostatic double probe

J. Vac. Sci. Technol. A 23, 551 (2005); 10.1116/1.1901666

Metastable and equilibrium phase formation in sputter-deposited Ti/Al multilayer thin films

J. Appl. Phys. 91, 9575 (2002); 10.1063/1.1477257

The new SR865 2 MHz Lock-In Amplifier ... \$7950

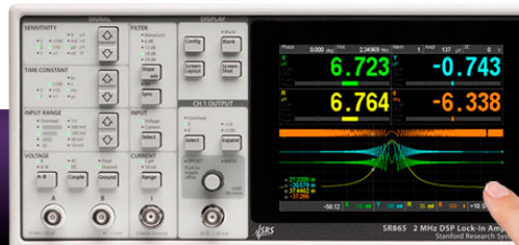

SRS Stanford Research Systems www.thinkSRS.com - Tel: (408)744-9040

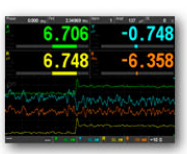

Chart recording

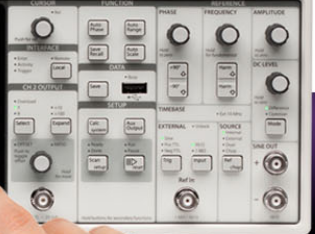

(2)

Intuitive front-panel operation

Touchscreen data display

- Embedded web server and iOS app

Synch multiple SR865s via $10 \mathrm{MHz}$ timebase I/O

View results on a TV or monitor (HDMl output)

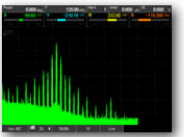

FFT displays

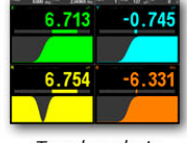

Trend analysis

$1 \mathrm{mHz}$ to $2 \mathrm{MHz}$

$2.5 \mathrm{nV} / \sqrt{ } \mathrm{Hz}$ input noise

$1 \mu$ s to $30 \mathrm{ks}$ time constants

$1.25 \mathrm{MHz}$ data streaming rate

Sine out with DC offset

GPIB, RS-232, Ethernet \& USB 


\title{
Effect of $\mathrm{N}_{2}$ and $\mathrm{Ar}$ gas on DC arc plasma generation and film composition from Ti-Al compound cathodes
}

\author{
Igor Zhirkov, ${ }^{1, a)}$ Efim Oks, ${ }^{2}$ and Johanna Rosen ${ }^{1}$ \\ ${ }^{1}$ Thin Film Physics Division, Department of Physics, Chemistry and Biology (IFM), Linköping University, \\ SE-581 83 Linköping, Sweden \\ ${ }^{2}$ Institute of High Current Electronics SB RAS, 2/3 Akademichesky Avenue, 634055 Tomsk, Russia
}

(Received 20 February 2015; accepted 20 May 2015; published online 1 June 2015)

\begin{abstract}
DC arc plasma from $\mathrm{Ti}, \mathrm{Al}$, and $\mathrm{Ti}_{1-\mathrm{x}} \mathrm{Al}_{\mathrm{x}}(\mathrm{x}=0.16,0.25,0.50$, and 0.70$)$ compound cathodes has been characterized with respect to plasma chemistry (charged particles) and charge-stateresolved ion energy for $\mathrm{Ar}$ and $\mathrm{N}_{2}$ pressures in the range $10^{-6}$ to $3 \times 10^{-2}$ Torr. Scanning electron microscopy was used for exploring the correlation between the cathode and film composition, which in turn was correlated with the plasma properties. In an Ar atmosphere, the plasma ion composition showed a reduction of $\mathrm{Al}$ of approximately 5 at. \% compared to the cathode composition, while deposited films were in accordance with the cathode stoichiometry. Introducing $\mathrm{N}_{2}$ above $\sim 5 \times 10^{-3}$ Torr, lead to a reduced $\mathrm{Al}$ content in the plasma as well as in the film, and hence a 1:1 correlation between the cathode and film composition cannot be expected in a reactive environment. This may be explained by an influence of the reactive gas on the arc mode and type of erosion of $\mathrm{Ti}$ and $\mathrm{Al}$ rich contaminations, as well as on the plasma transport. Throughout the investigated pressure range, a higher deposition rate was obtained from cathodes with higher Al content. The origin of generated gas ions was investigated through the velocity rule, stating that the most likely ion velocities of all cathode elements from a compound cathode are equal. The results suggest that the major part of the gas ions in $\mathrm{Ar}$ is generated from electron impact ionization, while gas ions in a $\mathrm{N}_{2}$ atmosphere primarily originate from a nitrogen contaminated layer on the cathode surface. The presented results provide a contribution to the understanding processes of plasma generation from compound cathodes. It also allows for a more reasonable approach to the selection of composite cathode and experimental conditions for thin film depositions. (C) 2015 AIP Publishing LLC.
\end{abstract}

[http://dx.doi.org/10.1063/1.4921952]

\section{INTRODUCTION}

Plasma generation from a cathodic arc discharge is commonly used for synthesis of wear resistant, decorative, and functional coatings. ${ }^{1}$ The main advantages of this technique are a high deposition rate and ability to operate in reactive atmosphere. $^{1,2}$ A common approach for materials synthesis is to mix two or more film-forming elements in a compound target from which plasma is generated. For instance, industrial physical vapor deposition (PVD) synthesis of (Ti,Al)N by cathodic arc evaporation from $\mathrm{Ti}-\mathrm{Al}$ compound cathodes ${ }^{3,4}$ in reactive atmosphere $\left(\mathrm{N}_{2}\right)$ is an established technique. ${ }^{5}$ Metastable $(\mathrm{Ti}, \mathrm{Al}) \mathrm{N}$ coatings have superior mechanical properties and oxidation resistance, ${ }^{6-9}$ and therefore serve as the archetype for wear-resistant and anti-corrosion material. However, despite the fact that many studies have focused on investigation of the correlation between various deposition parameters and the resulting properties of $(\mathrm{Ti}, \mathrm{Al}) \mathrm{N}$ thin films, see, e.g., Refs. 10 and 11, the correlation between cathode composition, plasma generation, plasma properties, and thin film synthesis in a reactive atmosphere is comparatively unexplored. Bilek et al., Ref. 12, described plasma composition,

\footnotetext{
a) Author to whom correspondence should be addressed. Electronic mail: igozh@ifm.liu.se. Phone +467305210 12. Fax +4613137568.
}

ion charge states, and ion energy distributions (IEDs) for filtered pulsed arc plasma generated from compound $\mathrm{Ti}-\mathrm{Al}$ cathodes in oxygen and nitrogen atmospheres. However, a magnetic field is known to strongly influence the plasma properties, see, e.g., Refs. 13 and 14, and no similar study has been reported for unfiltered DC arc plasma, a technique more commonly applied in industrial settings. ${ }^{1,15}$ Recent reports in literature contribute to an emerging description of arc plasma generation from compound cathodes, where a dependences of plasma properties on cathode elemental as well as phase composition are indicated. ${ }^{12,16-19}$ In our previous work, ${ }^{20}$ it was shown that for an unfiltered DC vacuum arc plasma from Ti-Al cathodes, the ion energy is dependent on the $\mathrm{Al}$ content, while the average charge state displays no significant change with cathode composition. Introducing a gas typically leads to loss of ion energy and ion scattering through interaction with gas particles ${ }^{21}$ as well as changes in plasma generation due to poisoning of the cathode in a reactive atmosphere. ${ }^{22}$ It is known that poisoning of the cathode transforms the arc spot from type 2 to type $1,{ }^{23}$ with resulting different plasma properties. For instance, plasma from type 1 spots typically has lower intensity, energy, and charge state of the ions, ${ }^{1}$ and is also characterized by a relative high amount of gas ions. The latter may influence the thin film deposition while providing additional energy to the substrate. 
However, the origin of these ions is still not unambiguously resolved. Therefore, a study of DC arc plasma generation from compound Ti-Al cathodes is highly motivated, aimed on an increased fundamental understanding of processes accompanying the arc discharge in a non-reactive/reactive atmosphere, and on an improved control of the film deposition process.

Here, we investigate the influence of $\mathrm{Ti}-\mathrm{Al}$ cathode composition, type of operating gas, and working pressure on the composition and properties of the ionized plasma as well as the thin film composition for a DC vacuum arc system. Absence of cathode surface reactions involving Ar excludes poisoning phenomena for this gas, and therefore aid in the interpretation of results from both an $\mathrm{Ar}$ and a $\mathrm{N}_{2}$ atmosphere. The absence of a macroparticle filter excludes effects from a magnetic field on the plasma properties, ${ }^{13,24}$ and therefore provides a base for fundamental understanding of arc plasma generation from $\mathrm{Ti}-\mathrm{Al}$ compound cathodes in a reactive and non-reactive atmosphere.

\section{EXPERIMENTAL DETAILS}

\section{A. Plasma analysis}

The experiments were performed using a deposition system with inner diameter $70 \mathrm{~cm}$ equipped with an industrial scale DC arc source for $63 \mathrm{~mm}$ diameter cathodes, including no separate anode. Experiments performed with and without the permanent ring magnets (intentionally not magnetized after extended use of the arc source), see Fig. 1, showed no significant change in results for any of the studied parameters here, hence, the value of the magnetic field at the cathode surface as well as its influence on the plasma generation was assumed insignificant. $\mathrm{Ti}, \mathrm{Al}$, and $\mathrm{Ti}_{1-\mathrm{x}} \mathrm{Al}_{\mathrm{x}}(\mathrm{x}=0.16,0.25$, 0.50 , and 0.70 ) cathodes were used, as produced by powder metallurgy. ${ }^{25,26}$

The cathodes were operated for at least $10 \mathrm{~min}$ prior to any measurements to exclude influence from initial contamination on the cathode surface on the experimental results and

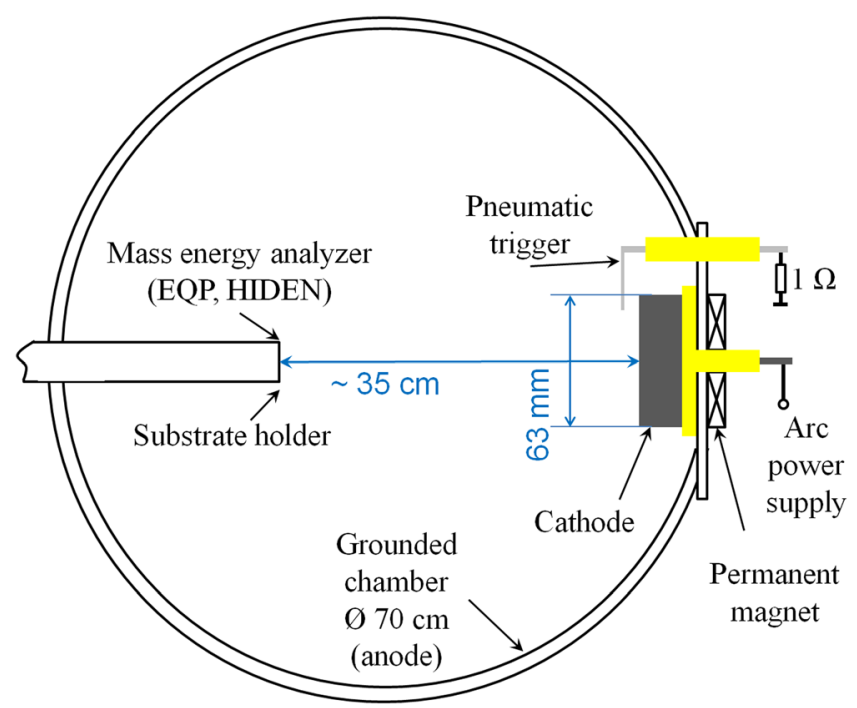

FIG. 1. Experimental setup, top view of the cylindrical deposition system. to reach steady state conditions, with no time dependence of the plasma properties. The arc current used in all experiments was $65 \mathrm{~A}$, and the base pressure (BP) was around $5 \times 10^{-6}$ Torr. The discharge voltage did not show any significant dependence on the cathode composition and only a minor influence from pressure, irrespective of choice of gas. The discharge voltage was changed from $\sim 21 \mathrm{~V}$ down to $17-18 \mathrm{~V}$ at the highest pressure, for all studied cathodes here. A mass-energy-analyzer (MEA, Hiden Analytics model EQP) was placed in front of the arc source with the orifice ( $50 \mu \mathrm{m}$ diameter) about $33 \mathrm{~cm}$ from the cathode surface. For each cathode, the plasma was characterized through massscans at fixed ion energy and energy-scans at fixed mass-tocharge ratio for all detected ions. The energy scans were recorded in steps of $0.25 \mathrm{eV} /$ charge up to $200 \mathrm{eV} /$ charge to capture the entire IED. Presence of isotopes in the ion flux and their influence on the relative ratios of the measured IEDs were evaluated according to previous work. ${ }^{20}$ Each IED was recorded at least three times to ensure consistency of the data. Over time, the MEA orifice may be coated and the recorded intensity reduced as an effect of reduced orifice size. To prevent such effect, the inlet channel was cleaned after final analysis from each cathode. To determine the plasma composition, the IEDs were integrated to obtain areas proportional to the number of ions of each species. Integral average energies, $E_{\text {avg }}$, were also calculated according to

$$
E_{\text {avg }}=\frac{\int I \cdot E \cdot d E}{\int I \cdot d E} .
$$

The average ion energies and the ratios between total intensities of IEDs of different ions in one cathode were found to be reproducible within $5 \%$.

\section{B. Film growth and characterization}

Films were deposited from the $\mathrm{Ti}_{0.25} \mathrm{Al}_{0.25}, \mathrm{Ti}_{0.5} \mathrm{Al}_{0.5}$, and the $\mathrm{Ti}_{0.3} \mathrm{Al}_{0.7}$ cathodes by fixing a $\mathrm{Si}(100)$ substrate in a position equivalent to the front end of the plasma analyzer, at grounded potential. Temperature calibration showed a substrate temperature not exceeding $250^{\circ} \mathrm{C}$. Compositions and thickness of the films were characterized using a LEO 1550 scanning electron microscope (SEM) equipped with energy dispersive X-ray spectroscopy (EDS). Film thickness and compositions were found to be reproducible within $10 \%$ and $5 \%$, respectively.

\section{RESULTS AND DISCUSSIONS}

\section{A. Characterization of metallic ions}

$\mathrm{Ti}$ and $\mathrm{Al}$ ions of charge states $1+, 2+$, and $3+$ were detected in the plasma from $\mathrm{Ti}, \mathrm{Al}$, and $\mathrm{Ti}-\mathrm{Al}$ cathodes, in both a $\mathrm{N}_{2}$ and $\mathrm{Ar}$ environment. For each gas, the investigated pressure range was $5 \times 10^{-6}$ Torr $-3 \times 10^{-2}$ Torr, with six different pressures selected for analysis. Even at the base pressure of $5 \times 10^{-6}$ Torr, no significant intensity was recorded for charge states of $4+$ and higher. Figure 2 shows 

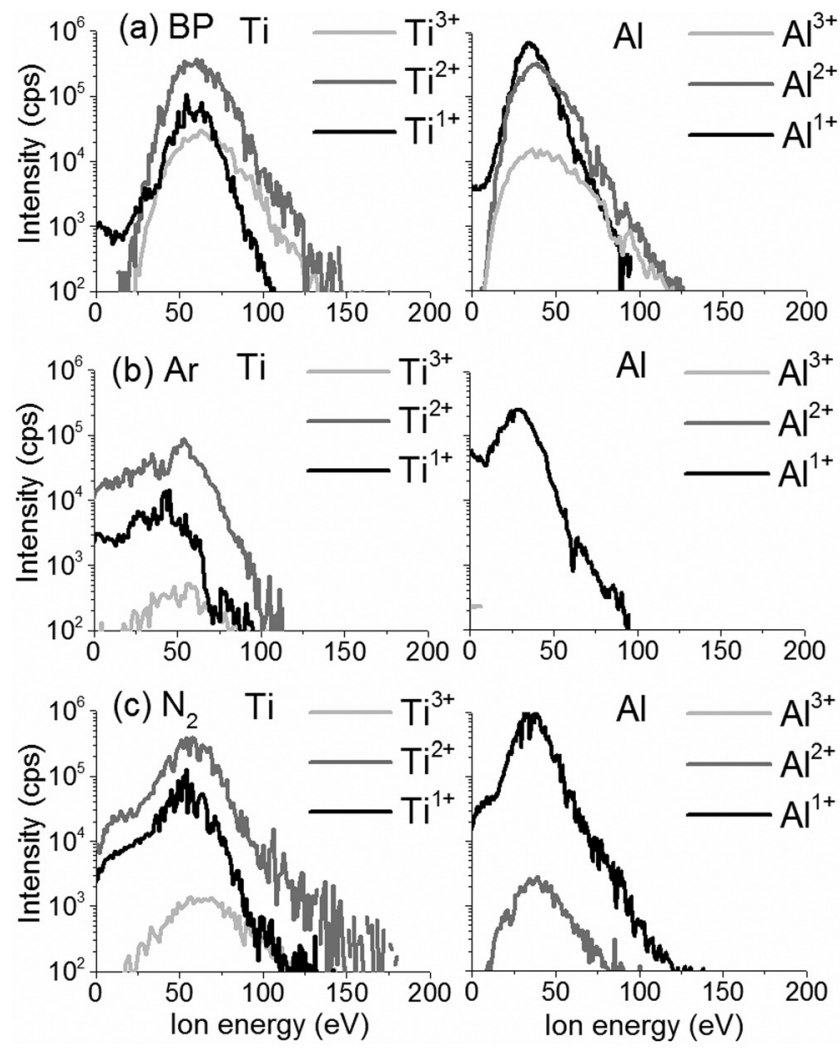

FIG. 2. IEDs of $\mathrm{Ti}$ (left) and $\mathrm{Al}$ (right) ions at the base pressure $5 \times 10^{-6}$ Torr (a) and at $5 \times 10^{-3}$ Torr of $\mathrm{Ar}(\mathrm{b})$ and $\mathrm{N}_{2}$ (c) in plasma from a $\mathrm{Ti}_{0.30} \mathrm{Al}_{0.70}$ cathode.

the IEDs obtained from the $\mathrm{Ti}_{0.3} \mathrm{Al}_{0.7}$ cathode at (a) BP and in (b) Ar and (c) $\mathrm{N}_{2}$ atmospheres.

Figure 2 clearly demonstrates the effect of pressure and type of gas on the IEDs. Independent on gas type, an increased pressure decreases the intensity of the higher charged metallic ions, most pronounced in an Ar atmosphere. Furthermore, at a relatively high pressure of $5 \times 10^{-3}$ Torr $\mathrm{N}_{2}$, the plasma consists of single and double charged ions of $\mathrm{Al}$, while in Ar, only single charged $\mathrm{Al}$ ions are detected.

\section{Effect of cathode composition and pressure on ion kinetic energy}

As shown in Fig. 3, the average kinetic energies of both $\mathrm{Ti}$ and $\mathrm{Al}$ ions remain roughly constant at low pressures, up to the "critical points" at $\sim 5 \times 10^{-3}$ Torr for Ar and $\sim 10^{-2}$ Torr for $\mathrm{N}_{2}$, for all investigated cathode compositions.

For pressures above the critical values, the average kinetic energies are reduced, see Fig. 3. However, the ion energy in the $\mathrm{Ar}$ atmosphere is decreased at lower operational pressure, and hence, the influence of Ar seems to be more pronounced, while $\mathrm{Ti}$ and $\mathrm{Al}$ ions remain more energetic in the $\mathrm{N}_{2}$ atmosphere.

As $\mathrm{Ar}$ is an inert gas, no cathode surface reactions involving Ar can be expected. Furthermore, in our previous study, ${ }^{20}$ we showed that possible formation of different intermetallic Ti-Al phases on the cathode surface, ${ }^{27}$ would lead to minor changes in the plasma properties, due to very similar physical properties of the cathode components. Therefore, it can be assumed that changes in plasma properties upon introduction
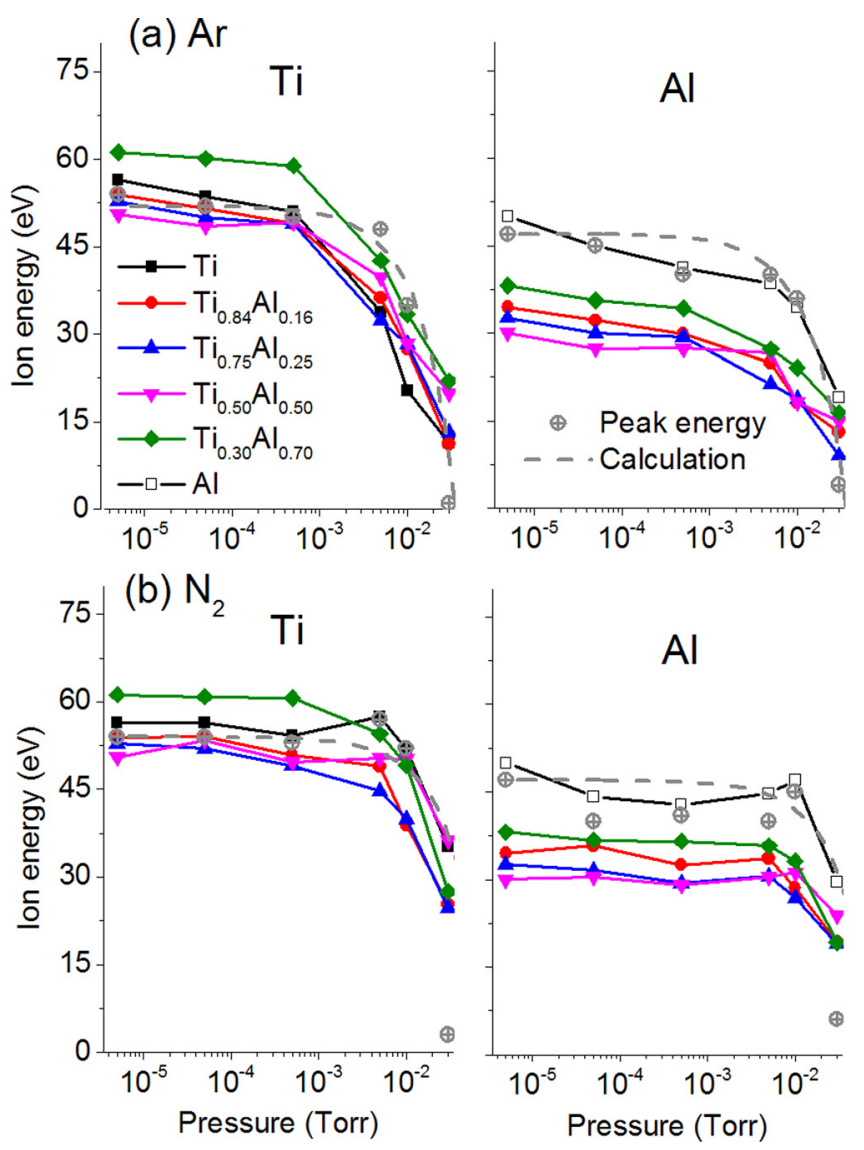

FIG. 3. Average kinetic energy of $\mathrm{Ti}$ (left) and $\mathrm{Al}$ (right) ions as function of pressure in $\operatorname{Ar}(\mathrm{a})$ and in $\mathrm{N}_{2}$ (b) atmospheres in plasma from different cathodes. Measured peak energies and corresponding calculated energies are presented for plasmas from pure $\mathrm{Ti}$ and $\mathrm{Al}$ cathodes.

of Ar are caused by collisional processes accompanying the expanding plasma. Collisions of the fast metallic ions with slow gas atoms or molecules will transfer energy and momentum to the gas, which at least in part, explains the decreased average ion energy with increasing gas pressure, see Fig. 3. If we consider the incident particles with mass $m_{i}$ and the gas particles with mass $m_{g}$, the change in the kinetic energy $\Delta E$ of the incident particles (assuming monoenergetic particles) is roughly 28,29

$$
\frac{\Delta E}{\Delta t}=-\mu \cdot E_{0} \cdot \gamma
$$

where $E_{0}$ is the ion energy before collisions, $\gamma$ is the transport collision frequency, $\mu$ is the energy transfer coefficient as given by $\mu=2 \cdot m_{i} \cdot m_{g} /\left(m_{i}+m_{g}\right)^{2}$, and $\mathrm{t}$ is the time. The transport collision frequency $\gamma$ can be determined as $\gamma=\vartheta_{i} / \lambda_{i},{ }^{21,28}$ where $\lambda_{i}$ is the mean free path. The time $\Delta \mathrm{t}$ can be estimated as the ratio between the distance $L$ between the cathode and the analyzer and the ion velocity $\vartheta_{i}$. Then the energy of the ions $E$ as function of $\lambda_{i}$ can be estimated as

$$
E=E_{0}\left(1-\mu \cdot \frac{L}{\lambda_{i}}\right)
$$

The mean free path can be written as $\lambda_{i}=1 /\left(n_{g} \cdot \sigma\right)$, where $n_{g}$ is the density of the gas particles and $\sigma$ is the collision cross-section. In turn, the density $n_{g}$ can be presented as 
$n_{g}=P /\left(k_{B} \cdot T\right)$, where $P$ is the pressure, $k_{B}$ is the Boltzmann constant, and $T$ is the temperature of the gas. Assuming that the ion energy in absence of any collisions $E_{O}$ is equal to the energy measured at base pressure, the dependence of the ion energy on the pressure can be estimated. The results are presented in Fig. 3 (dashed lines). The collision cross-section $\sigma$ is in the range of $10^{-19}-10^{-20} \mathrm{~m}^{-2}$ and, only weakly, depends on the ion velocity. ${ }^{28,29}$ A good correlation (see Fig. 3(a)) was found between the experimentally obtained dependences of the peak kinetic energy on Ar pressure, and the corresponding calculated dependence for $\sigma_{A r}=5 \times 10^{-20} \mathrm{~m}^{-2}$ (for both Ti and Al elements), which is very close to $6 \times 10^{-20} \mathrm{~m}^{-2}$ determined in Ref. 21 for $\mathrm{Cu}$ ions in $\mathrm{Ar}$ and $\mathrm{N}_{2}$ atmospheres.

For the $\mathrm{Ti}$ ions, the peak kinetic energies were not significantly changed with an increased pressure up to 5 $\times 10^{-3}$ Torr, see Figs. 2 and 3(a), while the average values shown in Fig. 3(a) demonstrate a somewhat stronger dependence on pressure. That discrepancy can be explained by the features on both sides of the peak energy in the IED. Fig. 2 shows that an increased pressure reduces the high energy tail and increases the intensity in the low energy range. Both these effects lead to a reduction in average energy. Expression 3 includes the energy of the incident particles. Therefore, even if the coefficient $\mu$ is the same for any two particles colliding with the slower gas atoms/molecules, the change will be higher for the particle with a higher energy. That could be a reason for the stronger, compared to the peak values, dependence of the average energies on the working pressure. It has to be noted that the peak value of the energy can be significantly changed only when the ratio between the length of the plasma transportation gap and the mean free path is close to " 1 " (see expression 1), while the average ion energy is changed when the collision probability is still relatively small.

For plasma generation in a $\mathrm{N}_{2}$ atmosphere, the critical pressure associated with pronounced changes in plasma properties is slightly higher than for Ar, see Fig. 3. It may be explained by the difference in the ratios of the ion mass and the gas atoms/molecules. ${ }^{21}$ However, the energy transfer coefficient $\mu$ is maximized when the mass of the incident ion is close to the mass of the slow particle. Therefore, it may be expected that in $\mathrm{Ar}$ atmosphere, (40 amu), the $\mathrm{Ti}$ ions (48 amu) loose more energy than $\mathrm{Al}$ during collisions. Correspondingly, in $\mathrm{N}_{2}$ (28 amu), $\mathrm{Al}$ (27 amu) transfers more energy to the gas particle. Fig. 3(b) shows that in the $\mathrm{N}_{2}$ atmosphere, both $\mathrm{Ti}$ and $\mathrm{Al}$ have higher "critical" pressures. From expression 3, a good correlation with experimental data can be achieved if the collision cross-section $\sigma$ is modified. In Fig. 3(b), the results of the calculation are presented for $\sigma_{N_{2}}=2 \times 10^{-20} \mathrm{~m}^{-2}$, which is two times smaller than for Ar. The lower collision cross-section can be used to at least in part explain the absence of a big difference between average and peak ion energies in the $\mathrm{N}_{2}$ atmosphere, see Fig. 3(b). The lower $\sigma$ implies a reduced probability for collision for all species in the ion flux. Therefore, the proportion of decelerated ions in the energy spectra (see Fig. 2) and, due to that, changes in the calculated averages, becomes smaller. The collision probability (the ratio between the length of the transportation gap and the mean free path) increases substantially with increasing pressure, note the logarithmic scale in Fig. 3, and as the probability reaches "1," it starts to influence the peak energy value as well. Also note that the expressions used for determination of $\gamma$ and $\lambda$ are approximations. $^{29}$

Up to the critical pressures, the dependences of the ion energy of the metallic ions on the cathode composition were found consistent with Ref. 20, where it was shown that the energy increases for an $\mathrm{Al}$ content higher than 50 at. \%. Furthermore, the peak energies of the metallic ions could be correlated through the "velocity rule,"17 stating that all ion species generated in the arc spot have the same peak velocities, see Ref. 20 for further details.

\section{Effect of cathode composition and pressure on ion charge states}

Figure 4 demonstrates that the charge state evolution of the metallic ions is very similar with respect to choice of gas.

Compared to the pressure dependence of the average kinetic energies, a reduction of the ion charge states occurs at higher pressure for $\mathrm{Ti}$ and at lower pressure for $\mathrm{Al}$. However, the reduction in average charge of the $\mathrm{Ti}$ ions becomes significant at the same critical pressure as for the peak kinetic energies. This could be caused by the loss of the kinetic energy, being significant after the critical pressure,
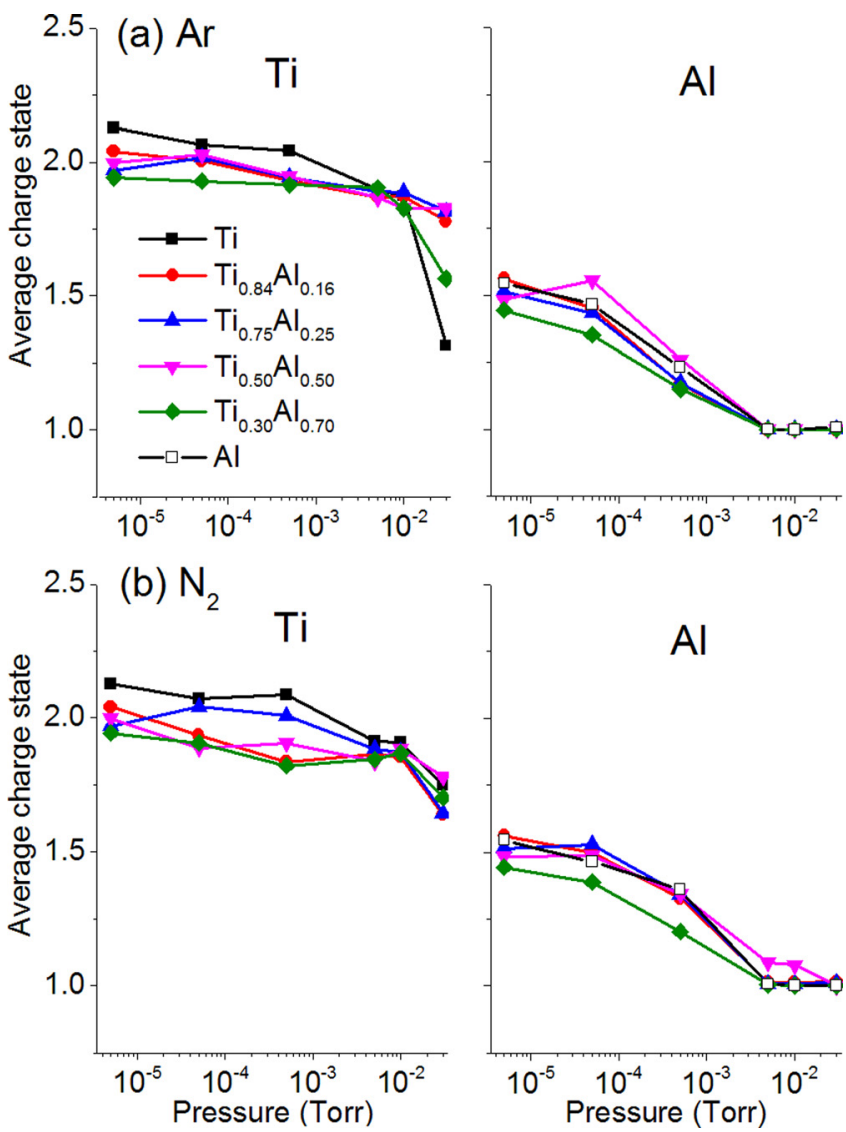

FIG. 4. Average charge states of $\mathrm{Ti}$ (left) and $\mathrm{Al}$ (right) ions as function of pressure in $\mathrm{Ar}$ (a) and in $\mathrm{N}_{2}$ (b) atmospheres in plasma from different cathodes. 
increasing the probability for charge reduction. Lower ion energy implies slower ions and therefore a longer time spent by the ions in the cathode-analyzer gap. Hence, the probability for processes leading to loss of charge increases. Also, the cross-section for resonant charge exchange collisions increases with a decrease in ion energy. ${ }^{30}$

The reduction in the $\mathrm{Al}$ ion charge occurs at lower pressures compared to both the peak and average kinetic energies. It is known that for the present pressure range, charge state reduction due to resonant charge-exchange interaction (between species of one element) has the highest probability to occur. The faster reduction in the charge state of $\mathrm{Al}$ (Fig. 4) could indicate that the neutral fraction of $\mathrm{Al}$ in the plasma increases more than for $\mathrm{Ti}$ with an increased pressure. One of the features of DC arc plasma is the relatively high number of neutral atoms, ${ }^{1}$ likely originating from evaporation from previously active arc spots on the cathode surface, ${ }^{31}$ evaporation from macro particles, ${ }^{32}$ and resputtering from previously deposited layers. ${ }^{33} \mathrm{Al}$ has a higher vapor pressure and lower boiling temperature than Ti (Ref. 34) which may suggest a disproportion of the elemental ratio in the neutral vapor, also supported by previously shown resputtering being more pronounced for lighter elements. ${ }^{35}$ The higher amount of the $\mathrm{Al}$ leads more intensive resonant charge-exchanges and, due to that, reduces the charge state of the $\mathrm{Al}$ in the plasma.

It should be noted that if we compare the ion charge states in DC and pulsed arc discharges, then the pulsed arc plasma typically displays slightly higher average charge state compared to DC arc. The discrepancy increases by reduction in pulse length (less than $100 \mu \mathrm{s}$ ). ${ }^{31}$ Furthermore, ion energy and ion velocities have also found dependent on the pulse length $^{36}$ for pulses shorter than $100 \mu \mathrm{s}$. However, usually thin film deposition is performed with pulse length in the range of $\mathrm{ms}$, where the discrepancy from DC arc is generally not significant. ${ }^{1}$ Therefore, we expect the identified trends and suggested explanations in the present paper to be applicable for both pulsed and DC arc.

\section{Correlation between cathode, plasma and film compositions}

The plasma composition (charged particles) as a function of working pressure is presented in Fig. 5 for four different cathode compositions. At base pressure and up to $5 \times 10^{-3}$ Torr, the Al content in the plasma is below the nominal cathode composition, with a discrepancy of around $5 \%$. As discussed in previous work, ${ }^{20}$ the discrepancy could be at least in part due to features of the used mass-energy-analyzer or different angular distributions for ions with different masses. ${ }^{37}$ For further details, see Ref. 20.

Despite the disagreement between cathode and plasma compositions, the compositions of the films deposited in the $\mathrm{Ar}$ atmosphere are in accordance with the cathode stoichiometry. However, an increased $\mathrm{N}_{2}$ pressure decreases the relative amount of $\mathrm{Al}$ in the films. Plasma characterization performed at the high $\mathrm{N}_{2}$ pressure also shows a reduced $\mathrm{Al}$ fraction in the plasma. At these conditions, the cathode surface is poisoned and a (partial) nitride layer is formed. As
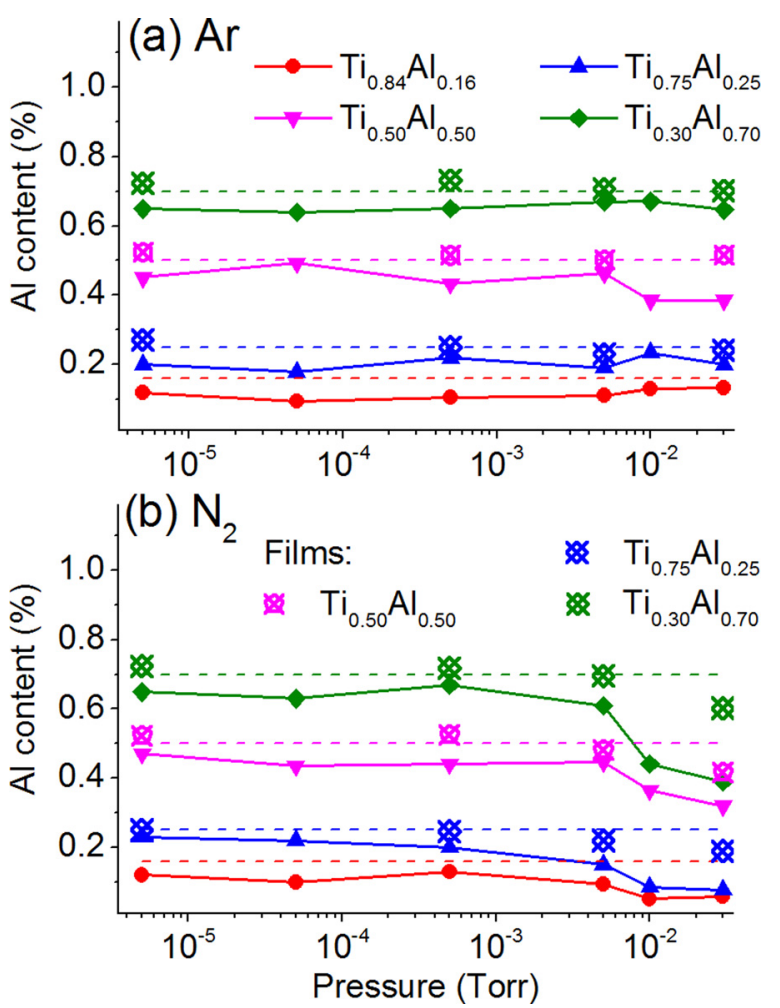

FIG. 5. Al content in plasma from different cathodes (solid lines), nominal cathode (dashed lines), and film (crossed points) compositions as function of pressure in $\operatorname{Ar}$ (a) and in $\mathrm{N}_{2}$ (b) atmospheres.

TiN has a significantly lower resistivity compared to AlN, there is a potential transformation of the spot type from type 2 to type 1, primarily for cathodes of higher $\mathrm{Al}$ content. This changes the conditions for plasma generation, and may explain the reduction of the $\mathrm{Al}$ content with increased pressure. For example, different spot types may have dissimilar ratios between the ionized and neutral fraction in the plasma. Also, the angular distributions of such fractions could be different. The analyzer orifice and the substrate holder were placed at the central axis of the system, and therefore any variation in the angular distribution of the elements could give a discrepancy between plasma, film, and cathode composition. It has to be noted that this discrepancy could be even more pronounced for depositions involving a substrate bias. Vetter et al. have shown ${ }^{38}$ that different sputtering yields of $\mathrm{Ti}$ and $\mathrm{Al}$ induce a significant depletion of $\mathrm{Al}$ in films deposited on biased substrates from $\mathrm{Ti}-\mathrm{Al}$ cathodes with an $\mathrm{Al}$ content up to 65 at. $\%{ }^{38}$ Therefore, to explain a reduction in $\mathrm{Al}$ content for reactive deposition of the $\mathrm{Ti}_{1-\mathrm{x}} \mathrm{Al}_{\mathrm{x}} \mathrm{N}$ films on a biased substrate, both changes in plasma properties in the reactive $\mathrm{N}_{2}$ atmosphere and depletion of $\mathrm{Al}$ by the higher resputtering yield should be considered.

Effect of working pressure on the total intensities of the metallic ions is presented in Figure 6, which shows that previously reported increase in efficiency of plasma generation/transportation at base pressure (in direction along the normal to the cathode surface) with addition of $\mathrm{Al}$ into the Ti cathode ${ }^{20}$ is not observed at the higher pressures. For an example, at $3 \times 10^{-2}$ Torr, a higher Al content in the cathode doesnot increase the number of detected ions in Ar and even decreases the ion intensity in $\mathrm{N}_{2}$. 

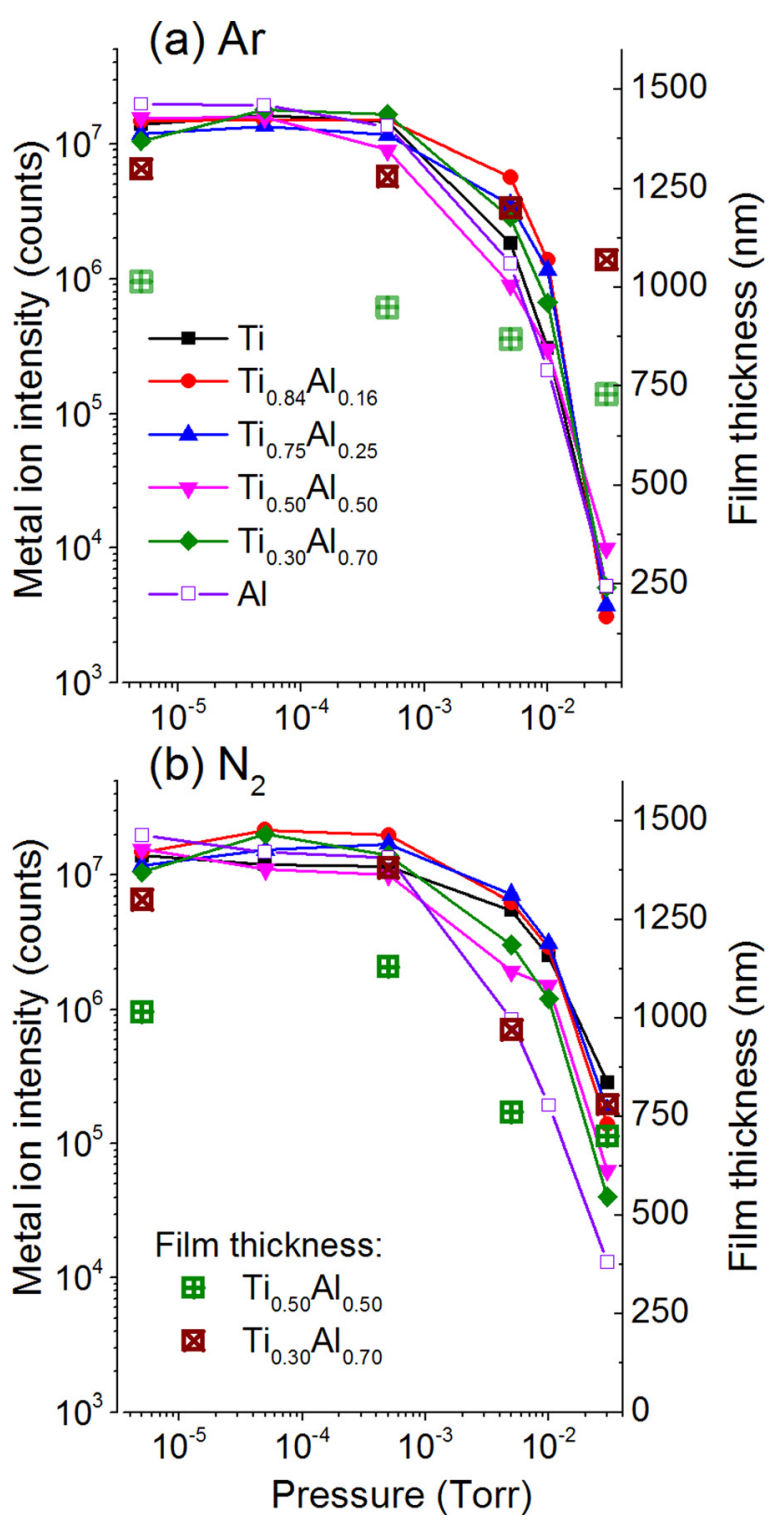

FIG. 6. Total intensities of the metallic ions (lines) and film thicknesses (squares) as a function of pressure in $\mathrm{Ar}$ (a) and $\mathrm{N}_{2}$ (b) atmospheres in plasma from different $\mathrm{Ti}-\mathrm{Al}$ cathodes.

The film thickness as a function of working pressure is also presented in Fig. 6, showing that the intensity of the metallic ions only partly influences the thickness of the resulting films.

Fig. 6 shows that $\mathrm{Ar}$ and $\mathrm{N}_{2}$ have only slightly different influence on the ion intensities, which remain close to constant up to critical pressures, comparable to those discovered for the average ion energies of the metallic ions in Figure 3 $\left(5 \times 10^{-3}\right.$ Torr for Ar and $1 \times 10^{-2}$ Torr for $\left.N_{2}\right)$. Therefore, for both the ion intensity and energy, collisions with gas particles are assumed to be the main mechanism behind the reduction. The influence of the type of arc spot considered above seems to influence primarily the relative ratio between the $\mathrm{Ti}$ and $\mathrm{Al}$ flux, and since the collision cross-sections for $\mathrm{Ti}$ and $\mathrm{Al}$ determined in Sec. III A1 are similar, the collision frequency determines the total plasma intensity.

From Fig. 6, it is obvious that the film thickness is more weakly dependent on the working pressure than the intensity of the metallic ions. Thicker films from the cathode with higher $\mathrm{Al}$ content may be explained by an increase in the number and size of macroparticles. ${ }^{20}$ On the other hand, it is known that the reactive $\mathrm{N}_{2}$ atmosphere reduces number/size of droplets form the arc spot. ${ }^{11}$ Considering that the film thicknesses in $\mathrm{Ar}$ and $\mathrm{N}_{2}$ (Fig. 6) are comparable, an explanation to these observations may instead be plasma-gas interaction and a growing number of collisions with gas particles. It is clear that metallic ions after such collisions change their trajectories and kinetic energies. Both these effects reduce the intensity of the ion flux at the substrate. A reduction in the average charge states (Fig. 4) suggests that an increased pressure increases the relative content of neutrals in the plasma. The neutrals are also affected by the collisions, however, not as strongly, since further charge state reduction and Coulomb interaction are not applicable. This may at least in part explain that the film thickness is less influenced by pressure compared to the ion intensity. However, also changes in the film density and possible incorporation of nitrogen/argon ions/neutrals may contribute.

The intensities from the pure $\mathrm{Al}$ and Ti cathodes in Fig. 6 show that in a $\mathrm{N}_{2}$ atmosphere, the intensity of the Al plasma decreases faster than for Ti. This observation is in agreement with previously reported difference between cathode erosion rates of $\mathrm{Al}$ and $\mathrm{Ti}$, and their dependency on the $\mathrm{N}_{2}$ working pressure. $^{22}$ The lower erosion rate of AlN could be explained by the entropy of formation of TiN and AlN being very similar $\left(\mathrm{TiN}=-323 \mathrm{~kJ} / \mathrm{mole}, \mathrm{AlN}=-319 \mathrm{~kJ} / \mathrm{mol}^{39}\right)$, while the temperature conductivity of $\operatorname{AlN}\left(180 \mathrm{~W} \cdot \mathrm{m}^{-1} \cdot \mathrm{K}^{-1}\right)$ is higher than for TiN $\left(26 \mathrm{~W} \cdot \mathrm{m}^{-1} \cdot \mathrm{K}^{-1}\right)$. Hence, higher amount of the energy will be dissipated in an AIN layer. The lower erosion rate of aluminum in $\mathrm{N}_{2}$ (Ref. 22) does not contradict that the elemental flux from a compound cathode used in steady state cannot be different from the cathode composition. Still, the cumulative elemental flux from the cathode is composed of macroparticles, ions, and neutrals, all contributing to the relative mass transfer of the elements and the growing film.

It has to be noted that plasma flux from arc spots of type 1 is characterized by a reduced intensity, average ion charge state, and kinetic energy as compared to type 2. Therefore, effects of the cathode poisoning on the behavior of all studied properties here could be expected. However, for the investigated conditions, it is not possible to strictly separate effects caused by poisoning and/or by features of plasma transport considered above. The ability of the arc discharge to switch between different types even during one pulse $(6-8 \mathrm{~ms})$ has been demonstrated. ${ }^{23}$ Since DC arc mode is used for the present investigation, switching of the arc type may occur frequently during the deposition process.

\section{B. The origin of gas ions}

Figure 7 shows the ion energy distributions of the detected gas ions. The amount of $\mathrm{Ar}^{2+}, \mathrm{N}_{2}{ }^{1+}, \mathrm{TiN}^{1+}$ ions was found insignificant and below $1 \%$ of the total plasma composition, for the pressure range investigated. Other ions, such as $\mathrm{N}^{2+}, \mathrm{AlN}^{1+}$, and $\mathrm{Ar}^{3+}$ could not be detected.

It is clearly shown that the intensity of the gas ions as well as their energy is much higher in a $\mathrm{N}_{2}$ atmosphere, 


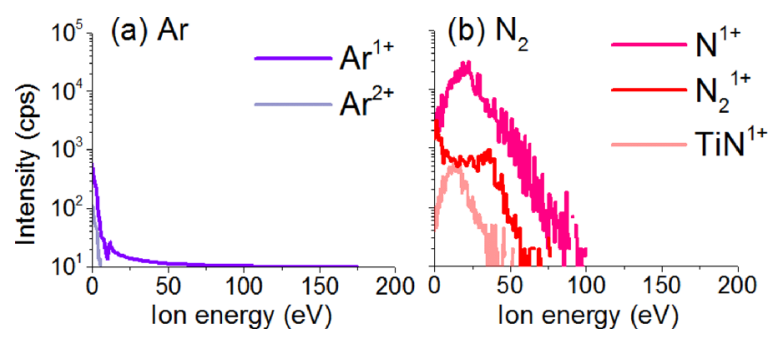

FIG. 7. IEDs of gas ions in $\mathrm{Ar}(\mathrm{a})$ and $\mathrm{N}_{2}$ (b) atmospheres at $5 \times 10^{-3}$ Torr in plasma from a $\mathrm{Ti}_{0.30} \mathrm{Al}_{0.70}$ cathode.

while the peak energy of $\mathrm{Ar}^{1+}$ is close to the initial point of the energy axis. This suggests that the main mechanism of Ar ionization is by impact with plasma electrons, which have relatively small kinetic energies in the range of a few eV. ${ }^{1}$ To explain the relatively high energy and intensity of the $\mathrm{N}^{+}$ ions, the "velocity rule"17 can be applied. The velocity rule states that the peak velocity (most likely velocity) of ions generated from a compound cathode is the same for all cathode elements. Therefore, this rule can be used also for detection of gas ions which originate from the cathode surface, and distinguish those from ions created during plasma transport. Table I shows peak ion energies $E_{\text {peak }}$ and corresponding peak ion velocities $V_{\text {peak }}$ in plasma from different cathodes at $5 \times 10^{-3}$ Torr $\mathrm{N}_{2}$ pressure.

It is clearly seen that within $\pm 5 \%$ error bars of the energy, the peak velocity of $\mathrm{N}^{+}$ions is comparable to the velocities of $\mathrm{Ti}$ and $\mathrm{Al}$ ions, and following any variation in velocities of the metallic ions. From these results, it can be concluded that the vast majority of the single charged ions of nitrogen is generated from nitrogen rich contaminations on the cathode surface.

The IED of molecular $\mathrm{N}_{2}{ }^{1+}$ presented in Fig. 7 shows that these ions have a peak value at the start of the energy axis. Hence, just as for the Ar ions, these are likely created primarily through electron impact. However, it can be seen that the IED of $\mathrm{N}_{2}{ }^{1+}$ extends up to a secondary peak value, equal to $33 \mathrm{eV}$, which corresponds to an ion velocity of $15 \mathrm{~km} / \mathrm{s}$. This value indicates that some of the $\mathrm{N}_{2}$ molecules were ionized in the arc spot volume and thereafter exposed to the same acceleration mechanisms as for the metallic and the $\mathrm{N}^{+}$ions.

$\mathrm{TiN}^{1+}$ ions have a peak around $13 \mathrm{eV}(6.5 \mathrm{~km} / \mathrm{s})$, see Fig. 7. The difference between the velocities of the ions from the arc spot, see Table I, and the $\mathrm{TiN}^{+}$ions, shows that the

TABLE I. Peak ion energies and velocities in plasma at $5 \times 10^{-3}$ Torr $\mathrm{N}_{2}$.

\begin{tabular}{|c|c|c|c|c|c|c|}
\hline & \multicolumn{2}{|c|}{$\mathrm{Ti}$} & \multicolumn{2}{|c|}{$\mathrm{Al}$} & \multicolumn{2}{|c|}{$\mathrm{N}^{+}$} \\
\hline & $\begin{array}{l}E_{\text {peak }} \\
(\mathrm{eV})\end{array}$ & $\begin{array}{c}V_{\text {peak }} \\
(\mathrm{km} / \mathrm{s})\end{array}$ & $\begin{array}{c}E_{\text {peak }} \\
(\mathrm{eV})\end{array}$ & $\begin{array}{c}V_{\text {peak }} \\
(\mathrm{km} / \mathrm{s})\end{array}$ & $\begin{array}{c}E_{\text {peak }} \\
(\mathrm{eV})\end{array}$ & $\begin{array}{c}V_{\text {peak }} \\
(\mathrm{km} / \mathrm{s})\end{array}$ \\
\hline $\mathrm{Ti}$ & 60 & 15.5 & $\ldots$ & $\ldots$ & 20 & 16.5 \\
\hline $\mathrm{Ti}_{0.84} \mathrm{Al}_{0.16}$ & 58 & 15.3 & 34 & 15.6 & 19 & 16.1 \\
\hline $\mathrm{Ti}_{0.75} \mathrm{Al}_{0.25}$ & 50 & 14.2 & 30 & 14.6 & 18 & 15.7 \\
\hline $\mathrm{Ti}_{0.50} \mathrm{Al}_{0.50}$ & 53 & 14.6 & 31 & 14.9 & 17 & 15.3 \\
\hline $\mathrm{Ti}_{0.30} \mathrm{Al}_{0.70}$ & 57 & 15.1 & 34 & 15.6 & 18 & 15.7 \\
\hline $\mathrm{Al}$ & $\ldots$ & $\ldots$ & 44 & 17.7 & 21 & 17 \\
\hline
\end{tabular}
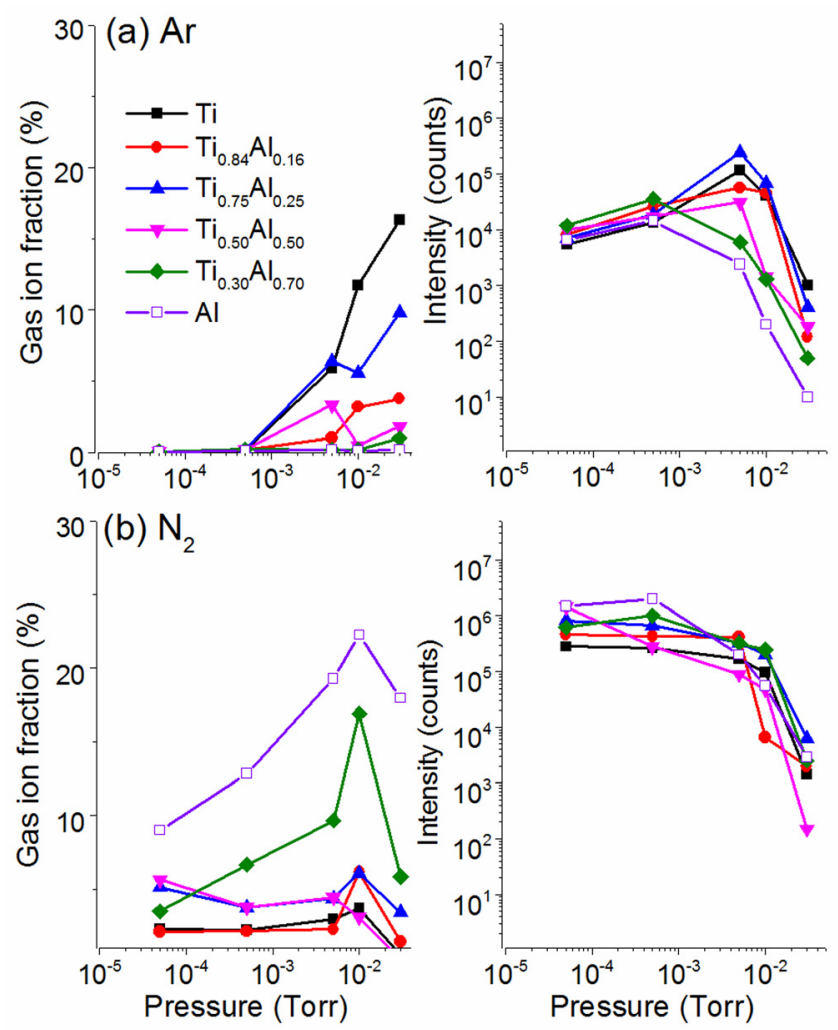

FIG. 8. Proportion and total intensity of gas ions in $\mathrm{Ar}$ (a) and $\mathrm{N}_{2}$ (b) atmospheres in plasma from different cathodes.

latter was likely not created in the spot. However, the peak itself indicates that $\mathrm{TiN}^{1+}$ ions were created through a chemical reaction, including fast and energetic ions. The reaction could occur between fast $\mathrm{N}^{1+}$ generated from the contamination on the cathode surface and slow neutral atoms of Ti, or, more likely, fast Ti ions and slow atomic or molecular nitrogen. However, such reactions are complex due to requirement of a third body to maintain conservation of energy and momentum.

The relative amount of the total intensities of the gas ions $\left(\mathrm{Ar}^{1+}, \mathrm{Ar}^{2+}, \mathrm{N}^{1+}, \mathrm{N}_{2}{ }^{1+}\right.$, $\left.\mathrm{TiN}^{1+}\right)$ is presented in Fig. 8, which shows that an increased proportion of $\mathrm{Al}$ in the cathode decreases the fraction of gas ions in $\mathrm{Ar}$ atmosphere, while in $\mathrm{N}_{2}$ atmosphere, the addition of $\mathrm{Al}$ in the cathode increases the gas ion fraction, to levels contributing significantly to the film growth. However, the trend for the corresponding total intensities of these ions (graphs to the right) is not as clear, supporting that the recorded ionized fraction of the plasma originates from a pressure-dependent interplay between plasma processes at the cathode surface and plasma-gas interaction during transport.

\section{CONCLUSION}

DC vacuum arc plasma from Ti-Al compound cathodes has been characterized with respect to ion composition, ion charge state, and ion energy in $\mathrm{N}_{2}$ and Ar atmospheres. It is shown that the proportion of $\mathrm{Al}$ in the ionic part of the plasma and the composition of concurrently grown films are independent on Ar pressure, and agree well with the cathode composition. On the contrary, introducing $\mathrm{N}_{2}$ above the 
"critical point" of $\sim 5 \times 10^{-3}$ Torr reduces the $\mathrm{Al}$ ion content in the plasma as well as in the resulting film, though thicker films were obtained from higher Al content cathodes throughout the pressure range investigated. The average energies of the metallic ions, $50-60 \mathrm{eV}$ and $30-40 \mathrm{eV}$ for $\mathrm{Ti}$ and $\mathrm{Al}$, respectively, remain close to constant up to 1 $\times 10^{-2}$ Torr $\mathrm{N}_{2}$ and $5 \times 10^{-3}$ Torr Ar. Therefore, the crosssection for collisions between metallic ions and the neutral gas was assumed as a bit higher for Ar compared to $\mathrm{N}_{2}$. The intensity of the metallic ion flux remained constant up to the just mentioned pressures, consistent with a thereafter increased ion-gas collision frequency and resulting in loss of energy and scattering. The average charge state of $\mathrm{Ti}$ and $\mathrm{Al}$ was found close to independent on type of used gas, though $\mathrm{Al}$ was more sensitive to pressure. This could imply a difference in generation of $\mathrm{Ti}$ and $\mathrm{Al}$ neutrals, leading to more frequent resonant charge-exchange processes for $\mathrm{Al}$.

Based on the "velocity rule," it can be concluded that the major part of $\mathrm{Ar}$ ions is generated through electron impact, while most of the gas ions in a $\mathrm{N}_{2}$ atmosphere originate from the cathode surface. The presented findings are of importance for the fundamental understanding of film synthesis involving compound cathodes, as plasma generation, ion charge states, and ion energies affect both compositional and structural evolution of the thin film.

\section{ACKNOWLEDGMENTS}

The Swedish part of this work was funded by the European Research Council under the European Community's Seventh Framework Programme (FP7/2007-2013)/ERC Grant Agreement No. 258509. J.R. acknowledges funding from the Swedish Research Council (VR) Grant No. 642-2013-8020 and from the KAW Fellowship program. Work of Russian coauthor Efim Oks is supported by Russian Scientific Foundation Grant No. 14-19-00083.

${ }^{1}$ A. Anders, Cathodic Arcs. From Fractal Spots to Energetic Condensation, 1 st ed. (Springer, New York, 2008).

${ }^{2}$ M. Kühn and F. Richter, "Characteristics in reactive arc evaporation," Surf. Coat. Technol. 89(1-2), 16-23 (1997).

${ }^{3}$ S. PalDey and S. Deevi, Mater. Sci. Eng. A 342, 58-79 (2003).

${ }^{4}$ A. Hörling, L. Hultman, M. Odén, J. Sjölén, and L. Karlsson, "Thermal stability of arc evaporated high aluminum-content $\mathrm{Ti}_{1-\mathrm{x}} \mathrm{Al}_{\mathrm{x}} \mathrm{N}$ thin films," J. Vac. Sci. Technol. 20, 1815 (2002).

${ }^{5}$ F. Weber, F. Fontaine, M. Sheib, and W. Bock, Surf. Coat. Technol. 177-178, 227-232 (2004).

${ }^{6}$ D. Mclntyre, J. Greene, G. Hakansson, E. Sundgren, and W. Munz, J. Appl. Phys. 67(3), 1542-1553 (1990).

${ }^{7}$ C. Jarms, H. Stock, and P. Mayr, Surf. Coat. Technol. 108/109, 206-210 (1998).

${ }^{8}$ W. Münz, J. Vac. Sci. Technol. A 4(6), 2717-2725 (1986).

${ }^{9}$ S. Danisman, S. Savas, and E. Topal, Tribol. Ind. 30(1/2), 17-22 (2008).

${ }^{10}$ Y. Chang, D. Wang, and C. Hung, Surf. Coat. Technol. 200, 1702-1708 (2005).
${ }^{11}$ M. Li and F. Wang, Surf. Coat. Technol. 167, 197-202 (2003).

${ }^{12}$ M. M. M. Bilek, P. J. Martin, and D. R. McKenzie, J. Appl. Phys. 83(6), 2965-2970 (1998).

${ }^{13}$ J. Rosén, A. Anders, S. Mráz, and J. Schneider, "Charge-state-resolved ion energy distributions of aluminum vacuum arcs in the absence and presence of a magnetic field,” J. Appl. Phys. 97, 103306 (2005).

${ }^{14}$ J. Rosen, A. Anders, and J. Schneider, "Plasma chemistry fluctuations in a reactive arc plasma in the presence of magnetic fields," Appl. Phys. Lett. 80, 4109 (2002).

${ }^{15}$ B. Coll and M. Chhowalla, Surf. Coat. Technol. 68/69, 131-140 (1994).

${ }^{16}$ K. Savkin, Y. Yushkov, A. Nikolaev, E. Oks, and G. Yushkov, Rev. Sci. Instrum. 81(2), 02A501 (2010).

${ }^{17}$ I. Zhirkov, A. Eriksson, and J. Rosen, "Ion velocities in direct current arc plasma generated from compound cathodes," J. Appl. Phys. 114, 213302 (2013).

${ }^{18}$ A. Eriksson, I. Zhirkov, M. Dahlqvist, J. Jensen, L. Hultman, and J. Rosen, J. Appl. Phys. 113(16), 163304 (2013).

${ }^{19}$ J. Sasaki and I. Brown, J. Appl. Phys. 66, 5198-5203 (1989).

${ }^{20}$ I. Zhirkov, A. Eriksson, A. Petruhins, M. Dahlqvist, A. Ingason, and J. Rosen, "Effect of Ti-Al cathode composition on plasma generation and plasma transport in direct current vacuum arc," J. Appl. Phys. 115, 123301 (2014).

${ }^{21}$ I. Beilis, A. Shashurin, and R. L. Boxman, "Measurement of ion flux as a function of background gas pressure in a hot refractory fnode vacuum arc," IEEE Trans. Plasma Sci. 35(4), 973-979 (2007).

${ }^{22} \mathrm{~S}$. Anders and B. Juttner, "Influence of residual gases on cathode spot behavior," IEEE Trans. Plasma Sci. 19(5), 705-712 (1991).

${ }^{23} \mathrm{~K}$. Jakubka and B. Juttner, "On the influence of surface conditions on initiation and spot types of unipolar arcs in a Tokamak," J. Nucl. Mater. 102, 259-266 (1981).

${ }^{24}$ J. Rosén, A. Anders, S. Mráz, A. Atiser, and J. Schneider, "Influence of argon and oxygen on charge-state-resolved ion energy distributions of filtered aluminum arcs," J. Appl. Phys. 99, 123303 (2006).

${ }^{25} \mathrm{P}$. Wilhartitz, S. Schönauer, and P. Polcik, "Method for producing an evaporation source," Patent EP1,335,995 (2003).

${ }^{26} \mathrm{G}$. Korb, "Process for the manufacture of a target for cathodic sputtering," U.S. patent 4,752,335 (1987).

${ }^{27} \mathrm{D}$. Rafaja et al., "Surface modification of Ti-Al targets during cathodic arc evaporation," Surf. Coat. Technol. 205, 5116-5123 (2011).

${ }^{28}$ V. Goland, A. Zhilinskiy, and I. Saharov, Plasma Physics (Original Russian Edition) (Atomizdat, Moscow, 1977).

${ }^{29}$ Y. Raizer, Gas Discharge Physics (Springer, Berlin, 1987).

${ }^{30}$ E. Oks and G. Yushkov, "Some features of vacuum arc plasmas with," in Proceedings of the 17th International Symposium on Discharges and Electrical Insulation in Vacuum (IEEE, 1996), Vol. 2, pp. 584-588.

${ }^{31}$ A. Anders, E. Oks, and G. Yushkov, "Production of neutrals and their effects on the ion charge states in cathodic vacuum arc plasmas," J. Appl. Phys. 102, 043303 (2007).

${ }^{32}$ G. Lins, IEEE Trans. Plasma Sci. 15, 552-556 (1987).

${ }^{33} \mathrm{~A}$. Anders, "Observation of self-sputtering in energetic condensation of metal ions," Appl. Phys. Lett. 85, 6137-6139 (2004).

${ }^{34}$ R. Honig and D. Kramer, RCA Rev. 30, 285-305 (1969).

${ }^{35}$ A. Eriksson, J. Zhu, N. Ghafoor, M. Johansson, J. Sjölén, J. Jensen, M. Odén, L. Hultman, and J. Rosén, Surf. Coat. Technol. 205, 3923-3930 (2011).

${ }^{36} \mathrm{~A}$. Anders and E. Oks, "Charge-state-resolved ion energy distribution functions of cathodic vacuum arcs: A study involving the plasma potential and biased plasmas," J. Appl. Phys. 101, 043304 (2007).

${ }^{37}$ A. Nikolaev, G. Yushkov, K. Savkin, and E. Oks, "Angular distribution ofions in a vacuum arc plasma with single-element and composite cathodes," IEEE Trans. Plasma Sci. 41(8), 1923-1928 (2013).

${ }^{38}$ J. Vetter et al., J. Adv. Mater. 31(2), 41 (1999).

${ }^{39}$ N. Zefirov, Chemical Encyclopaedia (Russian Encyclopaedia, Moscow, 1995), Vols. 1-5. 